\title{
New materials for the twenty-first century and the role of Tata Steel
}

\author{
JAMSHED J IRANI \\ Managing Director, Tata Steel, Jamshedpur 831001 , India
}

\section{Introduction}

Today there are tremendous opportunities for new materials and novel processing methods for existing materials to satisfy customer requirements. Materials have found place in every sphere of modern living like the construction sector, heavy engineering, automobile, aerospace, power, bio-engineering, microelectronics and so on. Developments in society and materials are interlinked as shown in figure 1 which reveals that the position has changed considerably over the centuries. The future success of industrialized countries would to a large extent depend on their ability to tailor various advanced materials to meet the critical demands of quality and performance of materials used in different applications. High-performance materials and their applications are the yard stick of expanding markets and the economic returns for those nations successful in bringing about changes in materials technologies are substantial. Various factors responsible for the changes in material technology are:

* Stringent demands for high quality and performance reliability of products.

* Competitive costing of manufactured components.

* Development of new products at a faster rate.

* Recyclability and the need to conserve material and energy resources.

* The need to protect domestic as well as international market shares.

In the coming decades there will be a dramatic change in the material menu on any designer's table and the dominating structural materials will be polymers, metals, ceramics, synthetic fibres, whiskers and particulate. The threat of competition and some loss of the market share to non-metallic materials has spurred the development of various kinds of sophisticated grades of steels, light weight aluminiumlithium alloys, etc. along with substantial efforts to restrict corrosion to the barest minimum if not eliminate it altogether in the material used. These developments in the type of material used have been accompanied by improved methods of processing various materials. Superplastic forming has reduced the complexity of manufacturing aerospace body parts for example, using both aluminium--lithium and speciality alloys.

The ideas and opportunities for new materials have never been greater-the reason is a science and engineering push combined with a market pull. Science and engineering have taken materials from the apparent plateau of the fifties and sixties of well-defined classes of homogeneous materials developed principally for their mechanical properties into the existing world of advanced materials catering to sophisticated markets. 


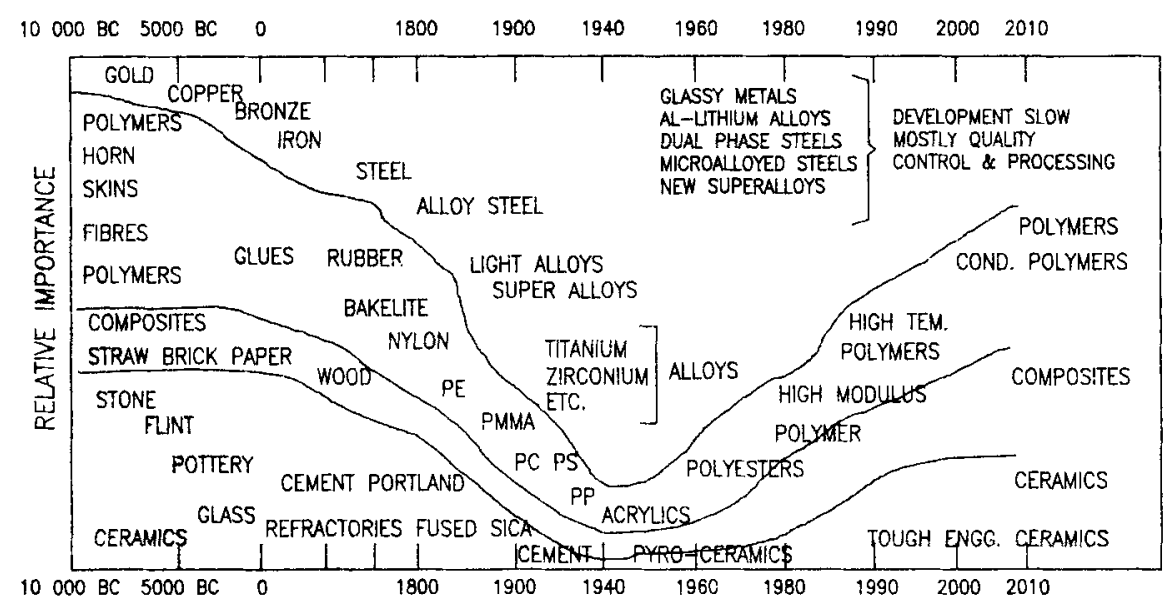

Figure 1. Evolution of materials: The relative importance of four classes of materials (polymers, composites, metals and ceramics) is shown as a function of time.

\section{New materials and their impact}

Table 1 depicts the development trends in some advanced materials. Newly emerging materials for specific applications can be grouped into several categories as shown below.

\subsection{Metallic materials and their specific applications}

* Functional gradient materials-spacecraft, nuclear reactors, etc.

* Shape memory alloys - biomaterials and sensors.

* Hydrogen occlusion alloys-hydrogen automobiles, heat pumps, etc.

* Amorphous materials-electronic components, transformers, etc.

* Extremely high heat resistant alloys-gas turbines, jet engines, etc.

* Powder metallurgy compacts-machine parts.

* Fibre reinforced metals-structural areas.

\subsection{Polymer materials and their targeted applications}

* High performance plastics or engineering plastic - machine parts (gears, bearings), cameras, electrical products, automobile bodies, construction materials, etc.

* Carbon fibre reinforced plastic (CFRP) and graphite fibre reinforced plastic (GFRP)-tanks, pipes, sporting goods, auto parts, etc.

* Electrical conducting plastic-office equipment, piezoelectric elements, audio equipment, etc.

* Separation membranes-medical equipment, bio-technology, water treatment and chemical industry.

* Water absorbing polymers - diapers, agriculture, civil engineering, etc.

* Liquid crystal polymers - optical fibres. 
Table 1. Examples of development trends in advanced materials.

\begin{tabular}{|c|c|c|}
\hline Application & Present technology & 21 st century \\
\hline \multicolumn{3}{|l|}{ Large structures } \\
\hline Bridge, oil-platforms & Microalloyed steels: $\mathbf{Q} \& \mathrm{~T}$ & Glass-fibre reinforced concrete \\
\hline Ships, submarines, & Microalloyed/CU-steels & Steel, titanium alloy, CFRPs \\
\hline Pipelines (oil or gas) & High purity steel & $\begin{array}{l}\text { Steel, high grade polymers } \\
\text { (thermoplastics) }\end{array}$ \\
\hline Cables & Patented steel $(0.8 \% \mathrm{C})$ & Carbon fibre strands \\
\hline \multicolumn{3}{|l|}{$\begin{array}{l}\text { High temperature, wear, } \\
\text { corrosion }\end{array}$} \\
\hline IC engines & Cast iron, $\mathrm{Al}-\mathrm{Si}$ alloys & Silicon nitride, PSZ/TZP, zirconia \\
\hline Gas turbine rotors & Ni-based super alloys & Ceramics; coated or bulk \\
\hline Machine tools & High alloy steels; WC-Co/TiN & Sialons; SiC ceramics \\
\hline Chemical plant & Austenitic stainless steel & Titanium alloys, ceramics \\
\hline \multicolumn{3}{|l|}{$\begin{array}{l}\text { Electrical, electronic, } \\
\text { optical, magnetic }\end{array}$} \\
\hline Power lines & $\mathrm{Cu}, \mathrm{Al} /$ steel reinforced & $\begin{array}{l}\text { Al-composites; Bi-based } \\
\text { superconductors }\end{array}$ \\
\hline Semi-conductor chips & Silicon, GaAs & More GaAs; doped polyacetylene \\
\hline Sensors (press, chem.) & As above (mainly $\mathrm{Si}$ ) & Laser engraved polymers; GaAs \\
\hline Chipboards & As above (2-dimensional) & 3-dimensional polymers or $\mathrm{Si} / \mathrm{GaAs}$ \\
\hline Fuel cells (solid) & $\mathrm{Al}_{2} \mathrm{O}_{3}$ & Doped polymers; $\mathrm{ZrO}_{2}$ \\
\hline Fibre optics & Graded composition silica fibres & Fluoride fibres \\
\hline Permanent magnets & Nd-Fe-B, ferrites & Polydiacetylene polymers \\
\hline \multicolumn{3}{|l|}{ Transport } \\
\hline Automobile bodies & Pressed steel & Aluminium, thermoplastics \\
\hline Aeroplane skins & Aluminium alloys: $\mathrm{Al}-\mathrm{Li}$ & Cellular CFRPs; Ti-alloys \\
\hline Railway wagon bodies & Steel, aluminium & GFRPs; cellular composites \\
\hline Bicycles & Steel, titanium alloy & Magnesium alloy, CFRPs \\
\hline \multicolumn{3}{|l|}{ Sport } \\
\hline Tennis, squash racqets & Aluminium, CFRPs & Carbon/Kevlar/SiC fibre FRPs \\
\hline Fishing rods & Bamboo, GFRPs, CFRPs & CFRPs with Kevlar/ceramics \\
\hline Surfing boards & GFRP/cellular CFRPs & CFRP/cellular Kevlar/SiC fibre \\
\hline \multicolumn{3}{|l|}{ Medical } \\
\hline $\begin{array}{l}\text { Hip joint, bone } \\
\text { replacement, tooth implant }\end{array}$ & Stainless steel, titanium & $\mathrm{Al}_{2} \mathrm{O}_{3}, \mathrm{Si}_{3} \mathrm{~N}_{4} \mathrm{SiO}_{2}$-bioglass \\
\hline
\end{tabular}

\subsection{New ceramic materials for specific applications}

* Alumina - medical implants, integrated circuits, etc.

* Non oxide ceramics - turbo chargers, fire proof materials.

* Zirconia - tools and crucibles.

* Superconductors - computer elements, medical appliances, linear motor cars, etc.

Developing economies are bound to face some serious consequences because of restructuring in the materials technology world and the implication is that a technology gap' would appear unless new materials and their manufacturing technologies are transferred to, or acquired by, the developing nations to gain market shares for value added products which meet customer specifications and costs. Technology import through various innovations, business approaches and linkages have been very 
effective in improving quality and cost competitiveness. In this connection R\&D linkages should become an important consideration in future relationships between developed and developing countries. It is worth mentioning here that low cost development oriented products are excellent candidates for this type of internal cooperation. Spray formed components, solar photovoltaics, plasma conditioning equipment and plasma synthesis of diamond films are some of the alternative areas which can be exploited towards this end.

\section{Outlook for steel}

At present steels are the most important group of materials for engineering applications. They are indispensable both in life saving applications like in surgical instruments as well as in huge structures like buildings, supertankers and bridges. Wherever we look, the safety of modern life crucially depends on the reliability of steels. But since steels have been in use as long as modern technology has existed, they are often wrongly regarded as 'old materials'. It is not sufficiently recognized that dramatic improvements are continually being achieved in steel, creating new grades with life cycles beginning with only about ten and going upto several years. The tremendous potential for innovation and improvement in this area stems from the vast chemical complexity of steels. Steel is far more than just iron-there are more than a dozen commonly used alloying elements in steel. This gives rise to an enormous number of significantly different combinations of compositions which are vastly larger than the existing number of steel grades thus providing a huge potential for future improvements. In addition, the strength and toughness of individual steel grades can be adjusted in wide ranges by simple heating, deformation and cooling treatments, further multiplying the possibilities of creating new properties and opening new regimes. Rapid solidification is one such example which has opened up a whole new area of transformer materials to existing steels purely by changing the cooling rate from the molten state to give rise to the desired microstructure. Similarly, considerable time and effort are being put into R\&D efforts to make tomorrow's steels better, safer and cheaper. Some of the promising areas are:

* New production technologies such as smelting reduction and near net shape casting, which have the potential to reduce investment cost, energy consumption and to improve environmental performance.

* The manufacture of semi-solid mixtures could soon reduce the temperature of processing and render some important steps in the production process more economical.

* Rapid solidification has opened the way to produce steels with new compositions and properties with the development of computerized controls.

* Flexible forming processes capable of producing different shapes without traditional tooling now seems likely to be applicable to steels.

* By applying a detailed understanding of the deformation mechanism, superplastic steels can be produced which can be stretched by more than $800 \%$ without tearing - an advantage in complicated forming processes.

* By improved surface technology, steel can be strengthened against wear and corrosion attack preferentially at the surface only, thus making it cost effective. New treatments like laser irradiation and electron bombardment are being developed to 


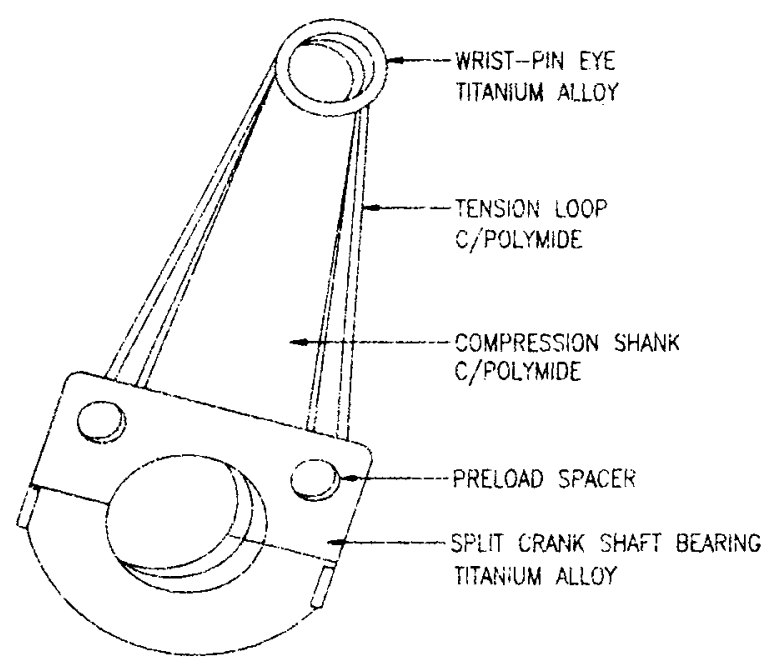

Figure 2. Hybrid polyimide titanium connecting rod developed by Daimlerbenz AG, Stuttgart, Germany.

tailor steel properties to given applications. In addition, the composition of the surface layer can be changed by new techniques like plasma spraying, physical vapour deposition, chemical vapour deposition and ion implantation. Even the deposition of diamond coatings has been achieved at moderate price using such techniques.

\section{Challenges to steel and the strategies to be adopted}

For the last few decades plastics, aluminium, cement and ceramics have invaded what was earlier strictly steel's province e.g. in the automobile, construction, canning and appliances industries. As a result, the steel industry all over the world has been compelled to meet this challenge by improving their products in various areas. The most widespread area in which steel is still pre-eminent is that of fasteners, as the properties of steel are ideally suited to the wide variety of nuts, bolts and washers covered by this broad description. Connecting rod is another component unlikely to move away from steel but very likely to see significant improvements in manufacturing processes. Progress has been made on sinter forged connecting rods to address the drawbacks of drop forging but these are still expensive. Daimler Benz has developed a hybrid carbon reinforced-polyamide titanium connecting rod, which weighs $30 \%$ less than its forged steel counterpart as shown in figure 2 . Although this hybrid is not practical for volume production, it may portend the eventual development of fibre reinforced plastic parts capable of extended service under high loads in the dynamic, hot and chemically aggressive engineering environment. Valve springs are a component for which anything other than steel seems inconceivable, but the need for improvements will grow with the demand for more effective use of space as valve accelerations go even higher and variable timing mechanisms become more applied. This will translate into a need for cleaner spring steel, since the majority of spring failures today arise from inclusions in the spring 


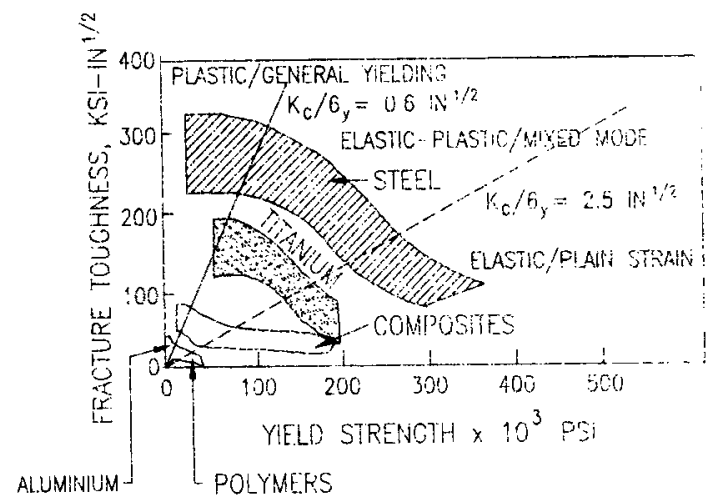

Figure 3. Comparison of various materials.

material. If the automobile industry can be considered as a barometer of a material's popularity, then one may see more of HSLA, interstitial free, bake hardening grades as well as new coated products. Although plastics may emerge as a future automotive material, some of the inherent problems associated with plastics like inconsistency in properties, recycling problems and poor crash worthiness must be tackled. On the other hand, steel can maintain its unchallenged position for certain components in the automobile industry if efforts are made in areas such as:

* Improved purity of steel, especially regarding metalloids such as phosphorus and sulphur and gases such as hydrogen, oxygen and nitrogen.

* Cleaner steel by elimination or control of inclusions.

* Homogeneity in all parts of a given steel product or, conversely, controlled differences between various parts of a given product.

* Achieving the exact shapes and dimensions especially in the precision of these dimensions.

\section{Development and status of advanced materials}

By the year 2000 the market for mechanical function metals and materials, e.g. sophisticated grades of steels, other metals and alloys along with metal composites will touch around 10 billion dollars. Intermetallic components which inherit properties in between metals and ceramics are being used in the development of new structural function materials, which possess high strength, toughness and heat resistance. Figure 3 shows a comparison of the properties of various materials. Metal matrix composites are also being developed in various areas including alloys of aluminium and titanium joined with carbon and ceramic fibres.

The forecast for various advanced materials also suggests that by the year 2000 , the demand for thermal function materials are expected to reach more than 250 billion dollars during the next decade. Materials for artificial joint and teeth for human implants, including different grades of stainless steel, could account for at least 7 billion of these 250 billion dollars.

The demand for electric and special electronic function materials will exceed 10 billion dollars and magnetic function materials requirement will be around 2.9 billion 
dollars in the next decade. With regard to miscellaneous function materials, such as laminate plates and other decorative facing materials, their anticipated growth and application potential will be simply phenomenal and the expected market would be 100 billion dollars or more.

The status of some other highly sophisticated advanced materials is given below.

\subsection{Functionally gradient materials (FGMs)}

A functionally gradient material is a substance in which the chemical composition and structure vary continuously on a macroscopic level, and it is sandwiched between ceramic, carbon and metallic materials having different properties. This high tech material is being manufactured using the concept of artificially providing gradient functions of two or three different materials without developing interface boundaries between the materials. These materials are being developed for application areas where combinations of properties like high resistance to heat, thermal stress, chemical attack and excellent mechanical strength are essential, like the body of the space shuttle, walls of a nuclear fusion reactor, optical fibres, etc. Thin film layer technology is most often used in various forms to produce FGMs.

\subsection{Hydrogen storage alloys}

A hydrogen storage alloy normally changes its volume while storing or releasing hydrogen. A lanthanum-nickel base alloy in amorphous form has recently been developed in Japan for hydrogen storage which functions for a long time period. The application of such alloys are in nickel hydrogen batteries, heat pumps, hydrogen and freon storage, etc.

\subsection{Shape memory alloys}

Shape memory alloys may be defined as alloys possessing an inherent capability to return to their original shape after undergoing deformation, irrespective of the extent of such deformation. This return to the original shape can be effected only by heating the alloy above a specific temperature. The initial shape is established in the alloy through appropriate heat treatment and very rigid compositional control during melting and processing of the alloy is essential. At present, two alloys- $\mathrm{Ni}-\mathrm{Ti}$ and $\mathrm{Cu}-\mathrm{Zn}-\mathrm{Al}$-have found industrial application in actuators, robotics and biomedical systems.

\subsection{Carbon fibres}

These were developed by Union Carbide, USA, by combusting cellulose fibres. Subsequently, carbon fibres were produced in Japan and UK by combusting polyacrylic nitrite (PAN) but the former now has a virtual monopoly in carbon fibre production methods. The most profitable applications of carbon fibres have been in the USA in the area of military and domestic aircraft structures. They are also being used in 
other areas like X-ray equipment, ceiling panels, X-ray films, cassettes, etc. In the new generation fighter aircraft, CFRPs are being used in the main wings because of their high strength, low density and resistance to chemical attack.

\subsection{Semiconductor and I.C. technology}

In the production of semiconductor and miniature electronics components, the current market share of Japan is 50 per cent whereas USA's share is 40 , the remaining 10 , being shared by others in Europe and Asia. The 256 kilobytes dynamic rapid access memory (DRAM) symbolized the backbone of Japanese strength in semiconductors; the next generation product is the one megabyte DRAM. The reason for such phenomenal success of Japanese companies in the acquisition of a large market share has been their ability to invest large amounts of money on a long range basis. A new generation chip which will eventually replace silicon semiconductors will be based on components such as gallium-arsenide (GaAs), and this new generation chip will be used in very high speed super computers and optical communications.

\subsection{Synthetic diamonds and coating/plasma technology}

Of late there has been a sharp increase with regard to the manufacture and use of synthetic diamonds. The major application areas are cutting wheels, grinding wheels and wear resistant components in which the hardness, chemical, optical and electronic properties of diamond are gainfully utilized. The optical properties of diamond have

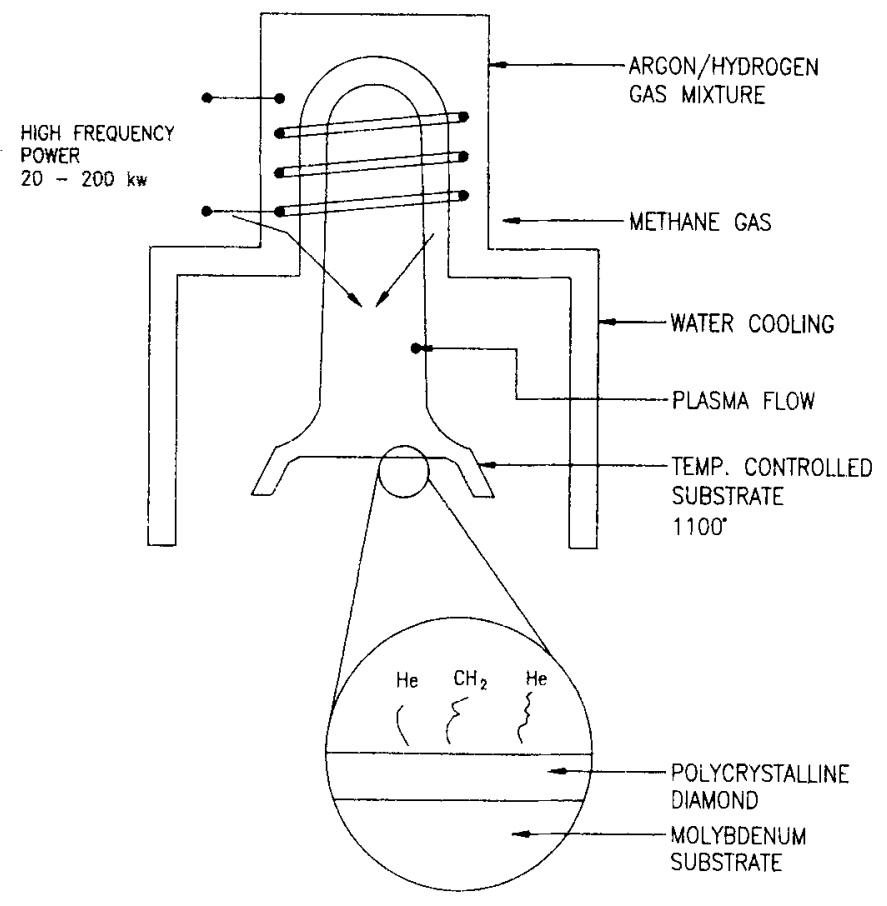

Figure 4. Diamond growth by induction plasma. 


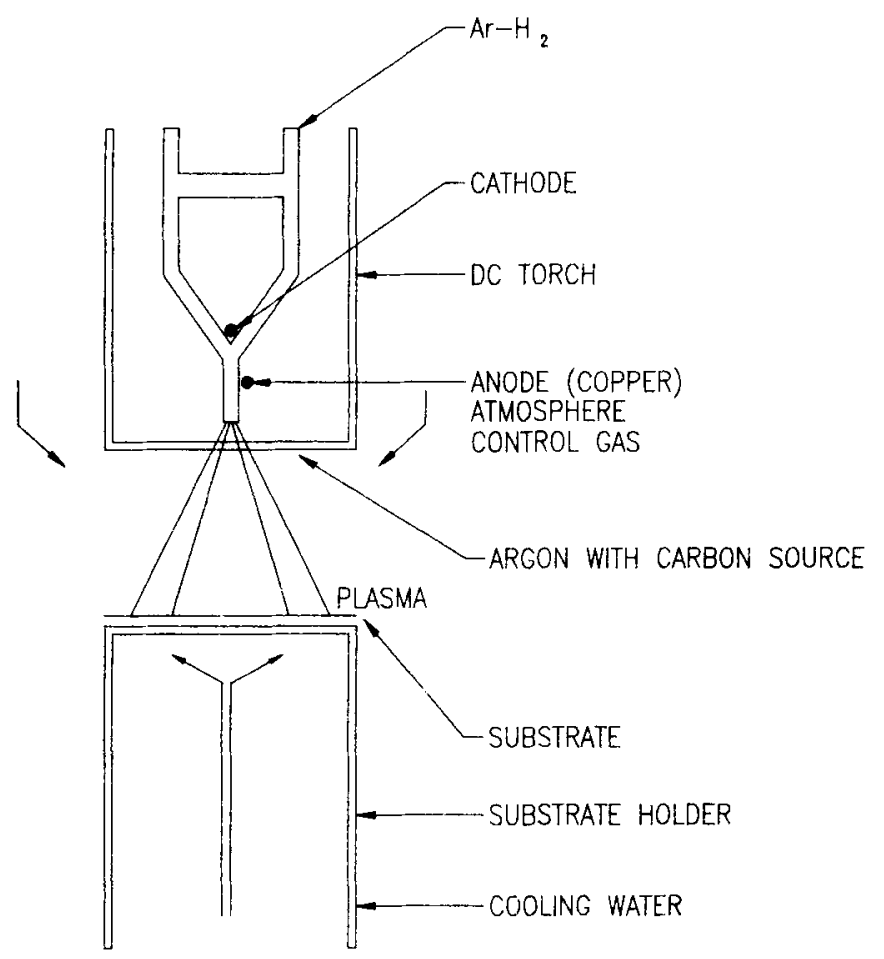

Figure 5. Schematic diagram of a DC plasma device.

raised considerable interest for applications of light abserption at various wavelengths when doped with other substances. It has been estimated that the market potential for synthetic diamonds could easily reach values exceeding 4 billion dollars by the year 2000 .

With regard to various coating technologies, vapour deposition methods have helped greatly in the synthesis of diamond thin films of large areas. Diamond thin films are produced from mixtures of methane and hydrogen gas at one atmosphere or lower pressure and a temperature considerably below $1500^{\circ} \mathrm{C}$ as shown in figure 4. The unique properties of diamonds are their transparency to light of almost any wavelength. electrical insulation and high thermal conductivity. A diamond can easily be turned into a semiconductor by adding impurity atoms. Interactions of microwaves under a magnetic field is one method of gas phase synthesis being used for plasma chemical vapour deposition (CVD). Diamond films from the gas phase have been formed at high speeds of 90 to 100 microns per hour, but it has to be remembered that all diamond related electronic devices are experimental in nature and the outcome of success is still speculative.

Synthesis of diamonds can also be done under high frequency plasma discharges; the characteristics and properties of diamonds synthesized by DC and HF plasmas are very similar as iliustrated in figures 5 and 6 , but cooling of the substrate has a profound influence on the precipitated diamonds since they can be easily changed to graphite if the substrate is improperly cooled. 


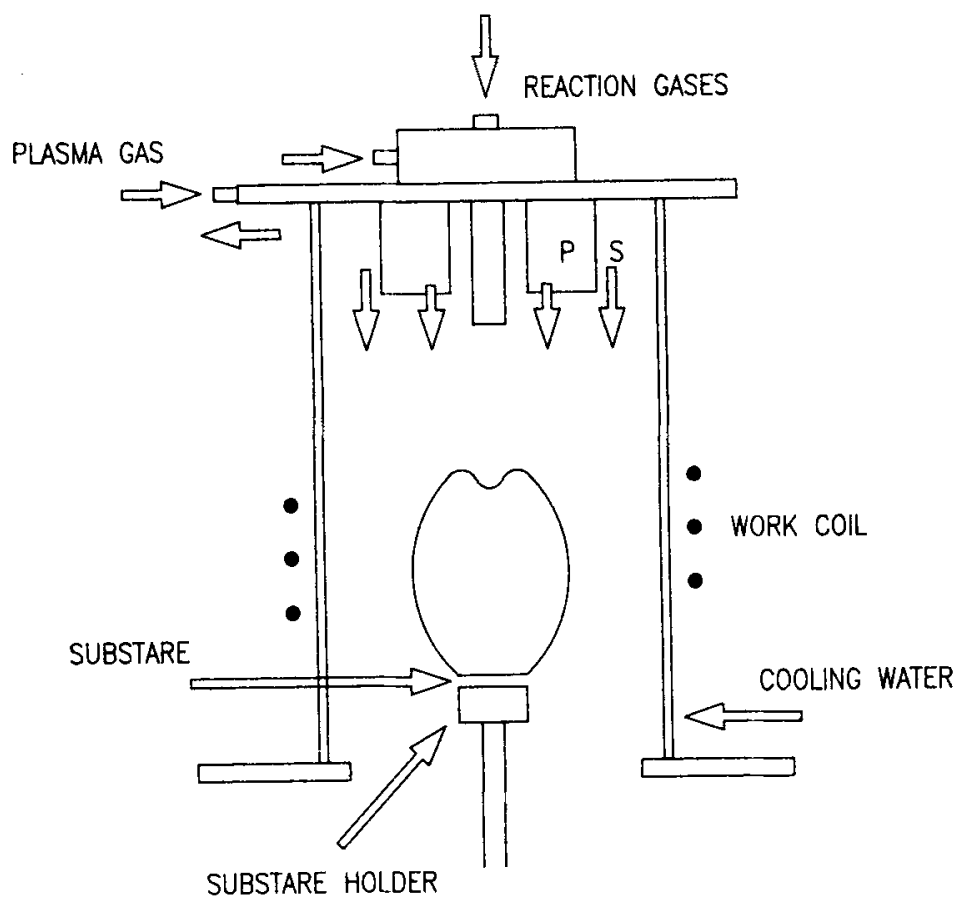

Figure 6. Sketch of plasma device.

\section{Pitfalls in the area of advanced materials}

At first glance many advanced materials promise great benefits, but a closer look reveals that many considerations have either been overlooked or ignored. The pitfalls involved include:

* Discussion of property improvement only on a relative rather than on an absolute scale.

* The use of inappropriate or carefully chosen adjectives that bias the merit of the materials.

* Discussion of new materials is often one dimensional (figure 7).

* Comparison of the properties of a new material with the current properties (as opposed to potential) of a traditional material.

* Ignoring processing considerations.

Of all these shortcomings, processing considerations may be the most perilous one. For example, materials science has progressed to a stage where carbon can be converted into diamond and lead to gold in the laboratory but such gold or diamonds are more expensive than what is found in nature. None of the new materials that are being developed will be useful unless they can be manufactured economically and this aspect is often lost sight of when elaborating the immense potential of many new materials.

\section{Tata steel's role in new materials}

Tata Steel has always been in the frontline of the defence of the steel bastion. It has fortified the position of steel against the onslaught of new materials with timely 


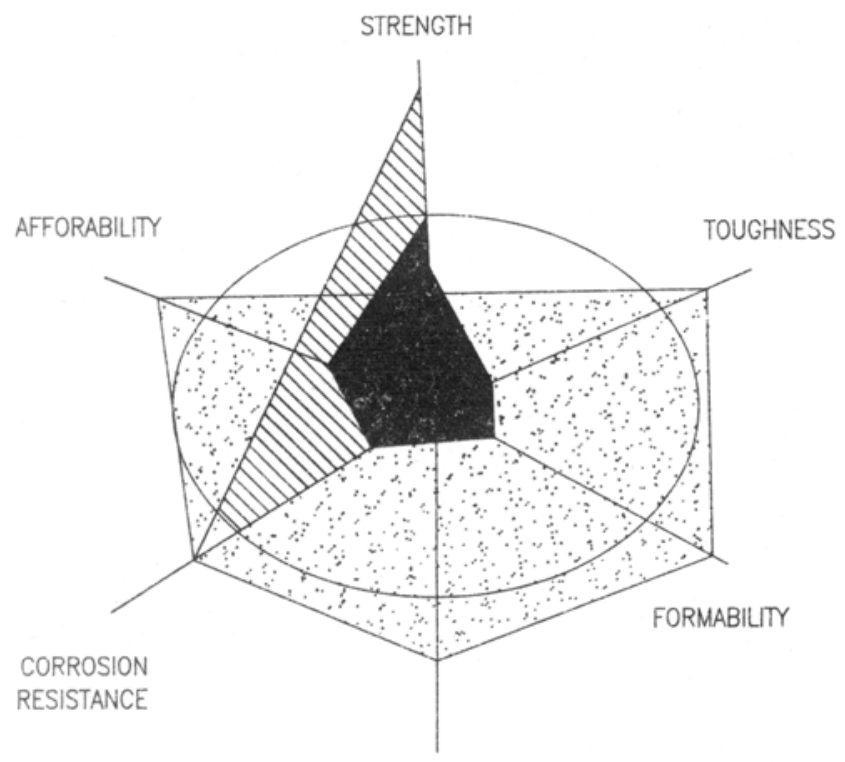

JOINABILITY

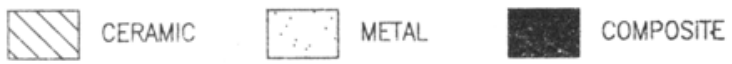

Figure 7. Citeria for material selection.

infusions of new technology, latest processing techniques and, above all, new products. Even though Tata Steel is the oldest integrated steel plant in India, a plant basically set-up to produce various sections and shapes of mild steel, with continuous improvement being made a way of life. the Company today is as young as many of the new kids on the block in the steel business.

Steel-making in the past had been more an art than a science and the steel-makers in Tata Steel's history had risen to the task again and again. of tailoring steels to particular applications. During World War I the entire eastern theatre, from Egypt to East Africa, had only Tata Steel as its source of steel supply. Steel from Jameshedpur, then called Sakchi, was used in making bomb shells, rails and armoured cars. This fire of entrepreneurship has been kept roaring by regularly stoking it with men, materials, machines and methods to keep Tata Steel at the leading edge of steel technology.

Back in the seventies, there was a pull from the market for forging quality steels. Even though such steels had never been made in the past in large tonnages and on a regular basis, a concerted effort was made to meet the challenge. Work was undertaken to introduce clean steel making methods, microalloy additions, improved soaking pit and rolling practices and, finally, better dressing and finishing operations. Similarly, there is a long list of other new products developed whenever there has been a demand from the market. The gamut of new steels developed in-house to fulfil market needs include:

* Steels for the automobile sector including spring steels for suspension and shock absorbers.

* High tensile steel plates for structural applications. 
* Steel sheets and strips for auto bodies, chains and electrical equipment.

* Creep resistant steel for boilers used in the electrical power sector.

* Steels for automobile forgings and load carrying members of automobiles.

* Cold heading quality steels for high tensile fasteners.

* Corrosion resistant reinforcing bars for the construction industry and corrosion resistant structurals for the railways and construction industry.

* Steels with toughness at sub-zero temperatures for use in structurals exposed to cold climates.

Such developments have also embraced the field of ceramics with materials like low cement castables, tar-dolo bricks, heavy duty alumina and ceramic filters having been developed in-house. The Company has also kept tabs on the developments taking place in the world of new materials. The potential of titanium had been studied thoroughly only recently and Tata Steel has also played a vital role in the development of nanocrystalline alumina powders. These powders can be used to make highly sophisticated parts resistant to chemical attack combined with appropriate strength. New processing methods like vapour deposition and ion implantation have been put to use in the area of tribology to combat wear and metal damage resulting in a four or five fold enhancement in the life of various components like liner plates, bushes, etc.

\section{Future direction}

Developments in materials science and engineering over the past few decades have been dramatic and the progress is expected to continue. There is no question that only a multi-dimensional approach, aided by cross fertilization of ideas will cater to the material challenges of the future. Sir Alan Cottrell, a renowned metallurgist, has said: 'Finally, quantum mechanics is beginning to explain engineering properties such as brittleness or ductility of crystals so that we are at last within sight of a unified science which starts at the Periodic Table and Schrodinger's equation and ends at practical materials for engineering use. Gearing up for the future in the materials manufacturing industries will require utilization of new materials and new manufacturing processes which will provide the results and guarantee the benefits.

International cooperation and strong interaction among industries, academia, financial institutions and governments is essential for the progress and well being of new materials in both developed and developing countries.

\section{Conclusions}

Being from the steel industry, it should not be surprising if I show a strong weakness for steel. Steel is not a single material; in fact, it is a composite. Steel has the advantages of many different types of materials to make it the most widely used material today, and this situation is unlikely to change in the foreseeable future.

J N Tata, the Founder of Tata Steel, established the Steel Company when steel in India was unheard of to such an extent that a certain wise Britisher had even stated that he would eat every ounce of steel made in India. If he had survived to see Tata Steel in full flow, he surely would have had 'severe indigestion'. Steel in India today is not only Tata Steel, but almost 28 million tonnes per year of crude steel is made in 7 integrated 
steel plants and a host of smaller units. India has one of the lowest per capita consumptions of steel. It is expected that by the turn of this century, Indian steel production would reach almost 35 million tonnes per annum. The outlook for steel is thus optimistic.

The expansion in the steel business is logical because steel is not really one material. There are various types of steels, some of which resemble glass while others are more akin to plastics and rubber in their combination of strength and ductility properties.

This is what makes steel a very versatile material and while it is envisaged that other materials will replace steel in certain functions, canning is an example which we have already seen, there are other applications like fasteners, for example, where steel can only be substituted by another type of steel. Looking forward to the twenty-first century, it is foreseen that steel will face challenges from alternative materials like plastic, aluminium, titanium, engineering ceramics, etc, but it will be able to weather the storm and the volume of steel production and its use, particularly in a country like India, would in fact increase. This is a sobering thought for someone like me engaged in the management of a steel company which has not only been the premier organization set-up in India, but has kept up with the times by developing new grades of steels as the years have gone by.

\section{References}

Metals and Materials 1992 Vol. 8

Advanced Materials and Processes July 1989

Advanced Materials and Processes May 1991

Industrial Heating September 1990

Tata Tech June 1993 